\title{
EDITORIAL
}

\section{SOCIEDAD Y CONOCIMIENTO}

a economía mundial, basada en conocimiento, la velocidad creciente de su re cambio, la vinculación efectiva entre productores y consumidores de ese conocimiento, así como la articulación entre innovación, ciencia y tecnología son, entre otras, algunas de las características y desafíos presentes en la sociedad actual.

Sin duda estas demandas recaen en los grupos profesionales, procurando mantener una educación continua o permanente, para reforzar competenciaso adquirir aqueIlas que les permitan desenvolverse en un mundo cambiante que los enfrenta a diario con materias desconocidas, con situaciones imprevistas y, por tanto, con retos nuevose inesperados.

En esteescenario, dondeel conocimiento juega un papel relevanteen la construcción de las sociedades, los órganos de difusión científica se constituyen en herramientas de trabajo indispensables para el desarrollo eficiente de los procesos propios de cada disciplina y la interacción entre las más diversas áreas y ciencias, cumpliendo así su función social.

La revista Ciencia y Enferm ería es una publicación que, desde su primer volumen editado en 1995, ha venido aportando ininterrumpidamente en esa dirección, cumpliendo en el próximo año una década de trayectoria. Como Presidenta del Consejo Asesor dela Revista, agradezco a la comunidad científica y profesional deenfermería losaportes y apoyos recibidos, como también expreso nuestro férreo compromiso al desarrollo de este órgano de difusión oficial del Departamento de Enfermería de la Universidad deConcepción.

\author{
Dra. Jasna Stiepovich Bertoni \\ Presidenta Consejo Asesor \\ REVISTA I BEROAM ERICANA DE INVESTIGACIÓN \\ Ciencia y Enfermería
}

